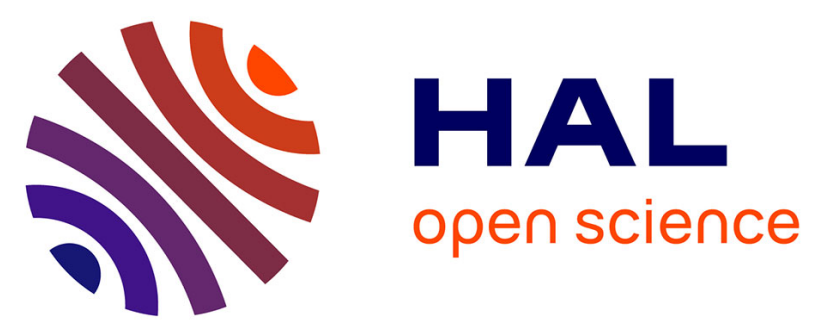

\title{
Identification of single nucleotide polymorphisms of the human metabotropic glutamate receptor 1 gene and pharmacological characterization of a P993S variant
}

Patrick M. Downey, Roberta Petrò, Jason S. Simon, David Devlin, Gianluca Lozza, Alessio Veltri, Massimiliano Beltramo, Rosalia Bertorelli, Angelo

Reggiani

\section{To cite this version:}

Patrick M. Downey, Roberta Petrò, Jason S. Simon, David Devlin, Gianluca Lozza, et al.. Identification of single nucleotide polymorphisms of the human metabotropic glutamate receptor 1 gene and pharmacological characterization of a P993S variant. Biochemical Pharmacology, 2009, 77 (7), pp.1246. 10.1016/j.bcp.2008.12.003 . hal-00493476

\section{HAL Id: hal-00493476 https://hal.science/hal-00493476}

Submitted on 19 Jun 2010

HAL is a multi-disciplinary open access archive for the deposit and dissemination of scientific research documents, whether they are published or not. The documents may come from teaching and research institutions in France or abroad, or from public or private research centers.
L'archive ouverte pluridisciplinaire HAL, est destinée au dépôt et à la diffusion de documents scientifiques de niveau recherche, publiés ou non, émanant des établissements d'enseignement et de recherche français ou étrangers, des laboratoires publics ou privés. 


\section{Accepted Manuscript}

Title: Identification of single nucleotide polymorphisms of the human metabotropic glutamate receptor 1 gene and pharmacological characterization of a P993S variant

Authors: Patrick M. Downey, Roberta Petrò, Jason S. Simon, David Devlin, Gianluca Lozza, Alessio Veltri, Massimiliano

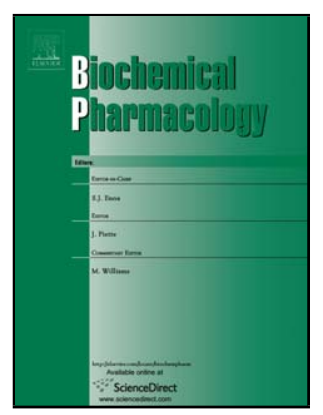
Beltramo, Rosalia Bertorelli, Angelo Reggiani

PII: S0006-2952(08)00893-9

DOI:

Reference: doi:10.1016/j.bcp.2008.12.003 BCP 10038

To appear in: $\quad B C P$

Received date: 4-11-2008

Revised date: $\quad 10-12-2008$

Accepted date: $\quad 11-12-2008$

Please cite this article as: Downey PM, Petrò R, Simon JS, Devlin D, Lozza G, Veltri A, Beltramo M, Bertorelli R, Reggiani A, Identification of single nucleotide polymorphisms of the human metabotropic glutamate receptor 1 gene and pharmacological characterization of a P993S variant, Biochemical Pharmacology (2008), doi:10.1016/j.bcp.2008.12.003

This is a PDF file of an unedited manuscript that has been accepted for publication. As a service to our customers we are providing this early version of the manuscript. The manuscript will undergo copyediting, typesetting, and review of the resulting proof before it is published in its final form. Please note that during the production process errors may be discovered which could affect the content, and all legal disclaimers that apply to the journal pertain. 
Identification of single nucleotide polymorphisms of the human metabotropic glutamate receptor 1 gene and pharmacological characterization of a P993S variant.

Patrick M. Downey, Roberta Petrò, Jason S. Simon*, David Devlin*, Gianluca Lozza, Alessio Veltri, Massimiliano Beltramo, Rosalia Bertorelli and Angelo Reggiani.

Schering-Plough Research Institute, Neurobiology Research, San Raffaele Science Park, Milan, Italy, and Discovery Technologies, Kenilworth, NJ.

Correspondence:

Dr Patrick Downey,

Schering-Plough Research Institute,

San Raffaele Biomedical Science Park,

Via Olgettina 58, 20132 Milano (Italy)

Tel. (00 39) 0221219205

Fax (00 39) 0221219242

E-mail patrick.downey@spcorp.com 


\begin{abstract}
mGluR1 receptors are believed to play major roles in the pathophysiology of diseases such as anxiety and chronic pain and are being actively investigated as targets for drug development. Sequence polymorphisms can potentially influence the efficacy of drugs in patient populations and are therefore an important consideration in the drug development process. To identify DNA sequence variants of the mGluR1 receptor, comparative DNA sequencing was performed on DNA samples $(n=186)$ from apparently healthy subjects representing 2 ethnic groups. In total, 8 non synonymous single nucleotide polymorphisms (SNPs) were identified and one SNP (c2977>T) was found to be particularly common, this SNP results in a Proline to Serine substitution at residue 993 (P993S). The WT (P993) and S993 variants were expressed in an inducible system which allowed us to titrate gene expression to equivalent levels and were pharmacologically characterised. We determined the potency and affinity of standard antagonist compounds as well as the potency and efficacy of the endogenous ligand Glutamate and other agonist compounds at both receptor variants. Agonist evoked increases in intracellular $\mathrm{Ca}^{2+}$ were measured by FLIPR. The potency of mGluR1 antagonists was evaluated by their ability to inhibit quisqualate induced increases in intracellular $\mathrm{Ca}^{2+}$, while their affinities were determined by radio-ligand binding studies. This study demonstrates that the Pro993Ser amino acid exchange is highly frequent in the human mGluR1 gene. This polymorphism however, does not appear to affect the potency of agonist compounds or the potencies or affinities of small molecule antagonist compounds.
\end{abstract}

Keywords:

metabotropic glutamate receptors; polymorphism; Pharmacogenetics; chronic pain; 


\section{INTRODUCTION}

Glutamate is the major excitatory neurotransmitter in the central nervous system, it produces its excitatory effects by acting on two classes of cell surface receptors, ligand gated cation channels known as ionotropic glutamate receptors and $G$ protein coupled receptors termed metabotropic glutamate receptors (1). Metabotropic glutamate receptors form a family of eight subtypes (mGluR1-8) which on the basis of structural homology, pharmacology and signal transduction mechanisms are subdivided into three groups (2). Group I receptors (mGluR1 and mGluR5) usually act postsynaptically to increase neuronal excitability (3). Excessive glutamatergic neurotransmission has been shown to underlie many CNS diseases and to play an important role in the pathophysiology of diseases such as depression, anxiety, and chronic pain, which represent key areas of interest for drug development. Accordingly, mGluR group I antagonists could represent useful agents for the treatment of these conditions. Indeed, in preclinical models, mGluR I antagonists have been shown to be very effective agents in the treatment of prolonged and chronic pain (4-6) and to possess anxiolytic activity $(7,8)$. Recent data suggests that mGluR1 antagonists may also be useful therapeutic agents for treating drug dependence (9) and depression (10). However, the involvement of mGluR1 in human CNS disorders has yet to be demonstrated, it is therefore important to carry out clinical proof of concept studies to understand the functions of mGluR1 in man. As a prelude to this type of activity it is important to understand the genetic variation within this receptor gene among human populations and within different ethnic groups.

Single nucleotide polymorphisms (SNPs), substitutions of a novel nucleotide for the wild type nucleotide within genomic DNA are the most common type of genetic variation and occur at a frequency of greater than $1 \%$ in the general population (11). Within the coding region of a gene, non synonymous SNPs, those that change the encoded amino acid sequence, can profoundly effect protein folding and disrupt post translational modifications (12). As far as GPCRs are concerned, there are a number of reports which show that non synonymous SNPS may also alter the normal functioning of the receptor by disrupting ligand-receptor binding (13) or altering the normal coupling to $\mathrm{G}$ proteins $(14,15)$. In some cases, SNPs may lead to increased disease susceptibility or yield variable responses to therapeutic agents. Therefore, evaluating the pharmacogenetics of disease-related targets is an important step in the drug development process.

The current study reveals the frequency of polymorphisms in the human mGluR1 gene and pharmacologically characterizes the very frequent P993S receptor variant. Despite the fact that eight non synonymous SNPs were identified, most were very rare and only the P993S variant was present at a frequency of greater than $5 \%$ in both populations. We have previously described the use of an inducible system, the Ecdysone system, to functionally express representative mGluR subtypes (16). Expressing the WT and S993 mGluR1 variants in this system allowed us to tightly regulate gene expression, so that we were able to express the two forms of the receptor at almost 
identical expression levels facilitating the functional analysis of the receptor variants. It has previously been demonstrated that non competitive antagonist compounds bind to the same binding pocket made from transmembrane helices IV-VII (17). All of the mGluR1 selective antagonists tested displayed similar potencies and affinities at the two receptor variants, it is therefore unlikely that the identified genetic variations would significantly modify the effectiveness of mGluR1 antagonists in man. 


\section{MATERIALS AND METHODS}

\subsection{Compounds}

Agonists, DHPG (3,5-dihydrophenylglycine); L-Glutamate; Quisqualic acid ((L)-(+)-a-Amino-3,5dioxo-1,2,4-oxadiazolidine-2-propanoic acid).

Antagonists, JNJ16259685, (3,4-dihydro-2H-pyrano[2,3]b-quinolinyl-7-yl)(cis-4-methoxycyclohexyl) methanone, LY456236, (4-methoxy-phenyl)-(6-methoxy-quinazolin-4-yl)-amine hydrochloride; All agonists and antagonists were purchased from Tocris Cookson (Bristol, UK), except for $\mathrm{SCH} 1041222$ which was synthesised by Schering Plough. Compounds were dissolved in HBSS or DMSO depending on their solubility. The final concentration of DMSO in all samples was compensated.

\subsection{Research Subjects}

To identify SNPs, the mGluR1 gene was sequenced from anonymous Caucasian $(n=47)$ and African American $(n=46)$ individuals. Genomic DNA samples were obtained from the Caucasian and African American human variation panels collected from the Human Genetic Cell Repository of the National Institute for General Medical Sciences (Coriell Cell Repository; Camden, NJ, USA). All samples came from individuals who provided informed consent to be part of the DNA polymorphism Discovery Resource. Information on geographic origin and gender was collected for each individual in order to assemble the DNA polymorphism Discovery Resource, but all identifying and phenotypic information has been removed from the individual samples.

\subsection{Polymerase chain reaction}

The general strategy for SNP discovery is as previously described (18) with modifications as detailed. PCR primers were designed using the Primer3 software (http://www.genome.wi.mit.edu/cgi-bin/primer/primer3.cgi) to amplify 400-650 bp segments of the GRM1 coding region, as well as approximately 100 nucleotides flanking the intron/exon splice junctions as determined by gaped alignment of the GRM1 coding sequence (Genbank accession no. NM 000838) with a finished genomic contig from chromosome 6 using sequencher ( $v 4.05$ Gene codes Corp, Ann Arbor, MI, USA). Forward and reverse primers were 5' tailed with universal primers -21 M13 5' TGTAAAACGACGGCCAGT and M13REV; CAGGAAACAGCTATGACC, respectively. PCR reactions contained genomic DNA (24ng in the presence of Platinum PCR supermix (100mM dNTPs $1.5 \mathrm{mM} \mathrm{MgCl}_{2}, 0,1 \mathrm{U}$ Platinum Taq polymerase (Invitrogen Corp, Carlsbad, CA, USA) and $0.2 \mathrm{pmol} / \mathrm{ml}$ forward and reverse primers in a $12 \mu \mathrm{l}$ total volume. Thermocycling was performed in 96 well microplates on a PTC.200 thermocycler (MJ Research; Waltham, MA, USA) with an initial denaturation of $94^{\circ} \mathrm{C}$ for $5 \mathrm{~min}$ followed by 35 cycles of denaturation at $94^{\circ} \mathrm{C}$ for $30 \mathrm{~S}$, primer annealing for $30 \mathrm{~s}$ and primer extension at $72^{\circ} \mathrm{C}$ for $1 \mathrm{~min}$, after 35 cycles a final extension was carried out for $7 \mathrm{~min}$ at $72^{\circ} \mathrm{C}$. 


\subsection{DNA sequencing and analysis}

Following DNA amplification, PCR amplicons were sequenced in the forward and reverse directions using $A B I$ PRISM BigDye terminator v3.1 Cycle Sequencing DNA Sequencing Kit (Applied Biosystems, Foster City, CA) on an Applied Biosystems 3730XL DNA Analyzer. Chromatograms were transferred to a Unix workstation (DEC alpha, Compaq Corp), base calling was performed with the Phred software (version 0.990722.g), sequences were assembled with the Phrap software (version 3.01) and scanned with the Polyphred software (version 3.5), and the results were viewed with the Consed software (version 9.0) (Phred, Phrap and Consed available at http://www.genome.washington.edu, PolyPhred is available at http://droog.mbt.washington.edu). Analysis parameters were all maintained at the software's default settings.

\subsection{Cloning}

CDNA was synthesised from human hippocampal mRNA (Clontech, Mountain View, CA) using the superscript kit according to the manufacturers (Invitrogen, Paisley UK) instructions. The coding sequence of mGluR1a was amplified from hippocampal c-DNA by PCR using a proofreading

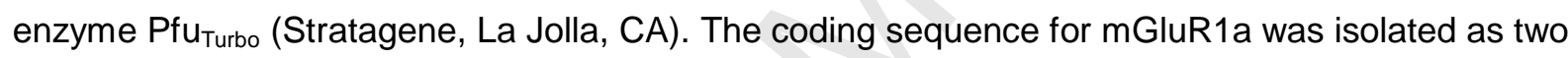
overlapping fragments using the following primer pairs, upstream Fwd 5' ATGGTCGGGCTCCTTTTGTTTTTTTTC $\quad$ 3' (1-27), upstream Rev 5' TTGGCAATGAGAGTGAATGGGCACA 3' (1928-1952), downstream Fwd 5'

ATAGCCATCGCCTTTTCATGCCTGG 3' (1783-1807), Downstream Rev 5'
TTACAGGGTGGAAGAGCTTTGCTTG 3' (3561-3588), the 5' and 3' fragments were cloned into pCRScript and fully sequenced on both DNA strands. After sequence confirmation the amplified products were joined together using the restriction enzyme Sac1 which has a single site within the mGluR1a coding sequence at nucleotide position 1890. The entire coding sequence was subcloned into pCRscript and the junction region was sequenced. To create the expression construct, the mGluR1 coding sequence was amplified using the following primers, Fwd 5' gAATTCgTCCTCACCACCATggTCgggСTCCTTTTgTTTTTTTTC 3', Reverse primer 5' gCggCCgCggATCCTTCCCCCTTACAgggTggAAgAgCTTTgCTTgTAgTCCC which contain an EcoR1 site and a full kozak sequence (forward primer) and a Not1 site (Reverse primer). The mGluR1a coding sequence was sub-cloned into the expression vector pIND (Invitrogen, Paisley UK) as an EcoR1-Not1 fragment, the construct was fully sequenced on both DNA strands.

\subsection{Creation of polymorphic variant}

The following primer pair was used to amplify a $1260 \mathrm{bp}$ fragment at the 3' end of the mGluR1a coding sequence from human hippocampal c-DNA, the amplified product extended from base pair 2340 to the end of the coding sequence 3588bp , FWD 5' CCgCCACgTgCCCgCCAACTTCA 3' 
Rev 5' gCggCCgcTTACAgggTggAAgAgCTTTgCTT 3', amplified products were cloned onto pCRScript (Stratagene, La Jolla, CA) and sequenced to determine clones with Thymine residues at position 2977 in the coding sequence, the P993 version contains a cytosine residue, the $\mathrm{C}$ to $\mathrm{T}$ change converts Proline into Serine. The coding sequence of mGluR1 contains a unique site for the restriction enzyme Nde1 at position 2724 and Plasmid pINDS993 containing mGluR1a-S993 was made by replacing the Nde1-Not1 restriction fragment from pINDP993 with the equivalent fragment from plasmid pCRScript-S993. The expression construct was completely sequenced in the region that had undergone restriction fragment swapping to confirm that only the intended mutation had been introduced.

\subsection{Isolation of clonal cell lines}

The HEK-293 $3_{\mathrm{ECR}}$ cell line (Invitrogen, Paisley UK), stably expressing the heterodimeric ecdysone receptor from the $\mathrm{pVgRXR}$ plasmid, was maintained in DMEM high glucose, supplemented with $10 \%$ foetal bovine serum (FBS), Pen/Strep, Glutamax ${ }^{\mathrm{TM}}$ (Invitrogen, Paisley UK) and 400 $\mu \mathrm{g} / \mathrm{ml}$ Zeocin ${ }^{\mathrm{TM}}$ (Invitrogen, Paisley $\mathrm{UK}$ ) at $3^{\circ} \mathrm{C}$, in an atmosphere containing $5 \% \mathrm{CO}_{2}$. Stable transfections with mGluR1a coding vectors, pINDP993 and pINDS993 were performed using Calcium Phosphate according to standard protocols. Stably transfected clones were obtained after selection with $550 \mu \mathrm{g} / \mathrm{ml}$ Geneticin ${ }^{\circledR}$ (Invitrogen, Paisley UK). During the induction of the receptor, cells were maintained in essentially the same culture medium except for the substitution of $5 \%$ dialysed serum and the addition of $3 \mathrm{U}$ GPT (Sigma) and 5mM sodium pyruvate.

\subsection{Binding}

Saturation binding experiments to membrane preparations were carried out in a total volume of $125 \mu \mathrm{l}$ of buffer $\left(50 \mathrm{mM}\right.$ Tris- $\mathrm{HCl} \mathrm{pH} \mathrm{7.4,} 1.2 \mathrm{mM} \mathrm{MgCl}_{2}, 2 \mathrm{mM} \mathrm{CaCl}_{2}, 0.1 \% \mathrm{w} / \mathrm{v}$ Bovine Serum Albumin) with a range of concentrations of $\left[{ }^{3} \mathrm{H}\right] \mathrm{SCH} 1041222$ (Schering-Plough Research Institute, $86.6 \mathrm{Ci} / \mathrm{mmol}$ ). The reaction was conducted at $25^{\circ} \mathrm{C}$ for 45 minutes and terminated by rapid vacuum filtration through GF/C filter-plates (Millipore, Italy) and three washing steps with ice-cold buffer. Dried filter-plates were counted with a Wallac Microbeta Trilux (Perkin Elmer, Wallac, Finland). Non-specific binding was defined in the presence of $10 \mu \mathrm{M}$ unlabelled SCH1041222.

$\mathrm{A}\left[{ }^{3} \mathrm{H}\right] \mathrm{SCH} 1041222$ displacement binding assay was performed to estimate the in-vitro affinities of the reference compounds LY456236 and JNJ16259685. The $\left[{ }^{3} \mathrm{H}\right] \mathrm{SCH} 1041222$ concentration was set to $2 \mathrm{nM}$. $K_{\mathrm{i}}$ values were calculated using the Cheng-Prusoff equation (19): $K_{\mathrm{i}}=I \mathrm{C}_{50} /\left[1+\left([\mathrm{C}] / K_{\mathrm{D}}\right)\right]$ (PRISM ® software, version 4.02). Reported $K_{d}$ and $B_{\text {Max }}$ values are the results of nonlinear regression analysis using Graphpad PRISM (GraphPad Software; San Diego, CA, USA). 


\subsection{Measurement of intracellular calcium transients}

Cells from clonal cell lines were seeded into black clear-bottom 96-well plates at a density of 60,000 cells/well, in DMEM high glucose supplemented with 5\% dialysed FBS, $3 \mathrm{U} / \mathrm{mL}$ GlutamicPyruvic Transaminase (GPT, Sigma, St. Louis, MO), $5 \mathrm{mM}$ sodium pyruvate, $5 \mu \mathrm{M}$ ponasterone A (Invitrogen, Paisley UK). Following $24 \mathrm{~h}$ incubation, the cells were loaded with a fluorescent calcium indicator (Molecular Devices, Sunnyvale, CA, USA). The dye was dissolved in the assay buffer which consisted of Hanks' balanced salt solution (Gibco Life Technologies) buffered with 20 mM Hepes solution (Sigma, St. Louis, MO). To avoid dye bleaching, $2.5 \mathrm{mM}$ Probenecid (Sigma, St. Louis, MO) was added to the calcium indicator solution. Cells were loaded with the dye for $2 \mathrm{~h}$ at $3^{\circ} \mathrm{C}$ in a $\mathrm{CO}_{2}$ incubator. A fluorometric imaging plate reader (FLIPR 384; Molecular Devices, Sunnyvale, CA, USA) was used to measure intracellular calcium by increases in fluorescence upon agonist stimulation following $30 \mathrm{sec}$-baseline measurement or 10 min antagonist administration. 


\section{RESULTS}

3.1. Genetic variation of the Human mGluR1 Gene.

The Human mGluR1 gene consists of a 3582 nucleotide open reading frame (ORF) divided into 8 exons spanning 409 Kilo base pairs on 6q24.3. Re-sequencing of the mGluR1 ORF, 5' and 3' UTRs and an average of $100 \mathrm{bp}$ upstream and downstream flanking the intron/exon splice junctions from an anonymous panel of Caucasian $(n=47)$ and African American $(n=46)$ subjects identified 46 SNPs. 17 SNPs were identified in the protein coding region of the gene, eight of which resulted in an amino acid substitution (Table 1), of these, only one SNP c2977>T (rs6923492: chr6:146797017 according to the March 2006 of the UCSC genome build) which results in an amino acid substitution P993S had an allele frequency of greater than $5 \%$ in both populations. This genetic variant occurred in exon 8 of the gene at a position corresponding to the $\mathrm{C}$ terminal intracellular tail of the receptor. The minor allele frequency was $28.3 \%$ in the African American samples, and $35.6 \%$ in the Caucasian samples.

\subsection{Expression of WT and P993S variant mGluR1a receptors in HEK-293 cells}

The coding sequence of the WT mGluR1a was isolated from hippocampal c-DNA and sub-cloned into the expression vector pIND. The $C$ to $T$ substitution at position 2977 of the mGluR1a cDNA clone (corresponding to 405804 ) was created by exchanging the Nde1-Not1 3' fragment of the WT pINDp993 expression construct with the equivalent fragment containing a thymine residue at position 2977. mGluR1 is a $\mathrm{Ga}_{\mathrm{q}}$-coupled receptor; its activation thus leads to an increase in intracellular calcium which can be measured using a fluorometric imaging plate reader (FLIPR). Clonal cell lines expressing the WT (P993) or the S993 variant of mGluR1 were initially prescreened for the stimulation of calcium mobilization in response to quisqualate following $24 \mathrm{~h}$ induction with $5 \mu \mathrm{M}$ Ponasterone A. A single clonal cell line for each receptor variant referred to as P993 or S993 respectively was chosen for further studies. To determine how receptor density can be modulated in these clones, cells were induced for $24 \mathrm{~h}$ with increasing concentrations (1-3-5 $\mu \mathrm{M})$ of Ponasterone $\mathrm{A}$ and saturation binding studies were performed to determine relative expression levels. The WT clone (P993) gave mean $B_{\text {Max }}$ values of $0.1,0,7,1.6,1.9 \mathrm{pmol} / \mathrm{ml}$, while the variant gave mean $B_{\text {Max }}$ values of $0,1,0.2,0.7$ and $1.55 \mathrm{pmol} / \mathrm{ml}$ respectively when induced with 0, 1, 3 and $5 \mu \mathrm{M}$ ponasterone A (See Figure 1 and Table 2). By varying levels of the inducer we were thus able to produce almost identical levels of expression for the WT and S993 cell line (mean $B_{\text {Max }}=1603 \mathrm{fmol} / \mathrm{mg}$ protein WT at $3 \mu \mathrm{M}$ ponasterone $A$ and $1550 \mathrm{fmol} / \mathrm{mg}$ protein S993 at 5uM ponasterone A). A functional characterization of the WT and variant clones was carried out under these conditions. 


\subsection{Functional Characterization of the WT and S993 variant.}

Saturation binding experiments performed using the non competitive antagonist SCH1041222 ( 20), did not highlight significant differences in antagonist binding, mean $\mathrm{K}_{d}$ values determined by saturation binding of this ligand were $0.873 \mathrm{nM}$ for the WT and $1.712 \mathrm{nM}$ for the $\mathrm{S} 993$ cell line at

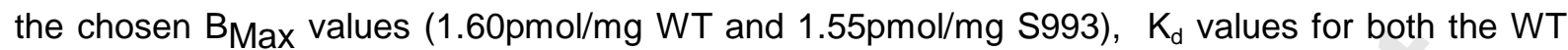
and 5993 cell lines at different $\mathrm{B}_{\text {Max }}$ values are shown in table 2. Furthermore when heterologous displacement experiments were performed using standard non competitive antagonists LY456236 (21) or JNJ16259685 (22), no significant differences in the affinity of these ligands were observed, mean $\mathrm{K}_{\mathrm{i}}$ values of $1.6 \mathrm{nM}$ WT and 3,7nM S993 for the JNJ16259685 compound and 375nM WT and 264nM S993 for the LY456236 compound were determined (Figure 2 a and $\mathbf{b}$ ). We also determined the potency of all of these non competitive antagonist compounds in functional calcium assays, quisqualate-induced $\mathrm{Ca}_{\mathrm{i}}{ }^{2+}$ release was tested in the presence or absence of LY456236, JNJ16259685 and SCH1041222 (Fig 3). When an agonist concentration corresponding to an $\mathrm{EC}_{80}$ value was utilised to stimulate the receptor, the addition of these reference antagonists resulted in a concentration-dependent inhibition of quisqualate elicited calcium signal with calculated $I_{50}$ values of 267nM LY456236, 2.3nM JNJ16259685 and 4.7nM SCH1041222 for the WT cell line and 445nM LY456236, 3.1nM JNJ16259685 and 5.2nM $\mathrm{SCH} 1041222$ for the $\mathrm{S} 993$ variant (Table 3). Here again we did not observe significant differences in the potencies of these compounds at the two receptor variants. The focus of the present study was to determine if the $\mathbf{S} 993$ polymorphism had an effect on the affinity or potency of antagonist compounds. However, given the fact that the polymorphic residue resides in the $\mathrm{C}$ terminal tail of the protein, it could effect $G$ protein/receptor coupling we therefore performed functional calcium assays with a number of agonist compounds. Again there were no significant differences, in either the potency or the efficacy of any of the compounds tested, ( Fig 4 for curves and table 3 ). 


\section{DISCUSSION}

It is widely recognised that different patients respond in different ways to the same medication and there are now numerous examples of cases in which inter-individual differences in drug response are due to sequence variants in genes encoding drug metabolizing enzymes, drug transporters or drug targets. Studies of genetic variation originally focused on drug metabolism but have now been extended to encompass the full spectrum of drug disposition, including a growing list of transporters that influence drug absorption, distribution and excretion (23). Most drugs exert their pharmacological effects by interacting with specific target proteins, molecular studies have revealed that many of the genes which encode drug targets exhibit genetic polymorphism, which in many cases alters their sensitivity to specific medications. Well characterised examples include polymorphisms in $\beta$-adrenergic receptors and their sensitivity to $\beta$-agonists in asthmatics (24), the angiotensin converting enzyme (ACE) and its sensitivity to ACE inhibitors (25) and the 5hydroxtryptamine receptor and response to neuroleptics such as clozapine (26). There is now an extensive and growing list of targets where polymorphisms have been linked to altered drug sensitivity, ongoing and future studies will undoubtedly expand the number of such pharmacogenetic relationships.

The metabotropic glutamate receptor family belongs to the class C GPCRs, and is the subject of intense investigation by pharmaceutical companies, as it is widely believed that the glutamatergic system plays a major role in the pathophysiology of clinically important diseases. mGluR1 antagonists represent potential therapy in a wide range of disorders including chronic pain, depression and anxiety and the patent and literature databases suggest that the development of such compounds is a very active field. However, studies investigating the occurrence of genetic variation within this receptor gene and the comparison of agonist and antagonist potency at different mGluR1 variants have not been published.

This is the first report of polymorphisms in the human metabotropic receptor 1 gene. Resequencing of mGluR1 in 93 DNA samples from apparently healthy subjects of African American or Caucasian ancestry identified 46 SNPs and 3 insertion/deletion polymorphisms. Of the 46 SNPS identified, 17 were in the coding region of the gene and 8 of those resulted in an amino acid change. This study demonstrates that while there are a number of non synonymous SNPs, most of these are very rare. Of the eight SNPs identified, four were only seen in the African American population and 2 were only observed in the Caucasian population, and all of these SNPs were present in less than $5 \%$ of their respective populations. Only 2 of the 8 identified SNPs were present in both populations and only the c2977>T (P993S) SNP was frequent in more than 5\% of each population. This variant was observed in $28.3 \%$ of the African American and $35.6 \%$ of the Caucasian alleles respectively. The sample size used in this study was sufficiently powered to ensure identification of $99 \%$ of all SNPs present in either population at a minor allele freq of $5 \%$ or greater (11). The polymorphism described here, S993, occurs in the Intracellular C terminal part of 
the receptor. mGluRs bind glutamate and other agonists at an extracellular amino terminal domain (27), while non competitive antagonists bind to a trans-membrane portion of the receptor (17). G protein/receptor coupling has been largely attributed to interactions between the second and third intracellular loops of the receptor and the $C$ terminus of the $G$ Protein $(28,29)$, Amino acids crucial for binding non competitive antagonists of the human mGluR1 receptor reside in the transmembrane segments V-VII (17) and are thus located relatively far away from the polymorphism evaluated in this study. Although it cannot be excluded apriori that substitution of distant residues could evoke allosteric conformational changes in the antagonist binding pocket, it is not unduly surprising that the potency and affinity of these compounds does not differ between the $\$ 993$ variant and the wild type receptor. Our results indicate that only the $\$ 993$ polymorphism occurs frequently within the mGlu1 receptor and that this polymorphism does not significantly affect either antagonist affinities or potencies nor does it alter agonist potencies. However, it remains to be determined whether this SNP would play a role under pathological conditions or during neuronal plasticity. On balance, we believe that the identified genetic variations are unlikely to reduce the effectiveness of mGluR1 antagonists if and when such compounds eventually reach proof of concept studies in man 


\section{REFERENCES}

(1) Kew JNC and Kemp J . Ionotropic and metabotropic glutamate receptor structure and pharmacology. Psychopharm 2005; 179: 4-29

(2) De Blasi A, Conn PJ, Pin J-P, Nicoletti F. Molecular determinants of metabotropic glutamate receptor signaling. T I Ps 2001; 22: 114-120

(3) Gasparini F, Kuhn R, Pin J-P. Allosteric modulators of group I metabotropic glutamate receptors: novel subtype-selective ligands and therapeutic perspectives. Curr Opin Pharm 2002; 2: 43-49

(4) Scheryantz JM, Kingston AE, Johnson MP. Prospects for metabotropic glutamate I receptor antagonists in the treatment of neuropathic pain. $J$ Med Chem 2007; 50: 25632568

(5) Bhave G, Karim F, Carlton SM, Gereau RW. Peripheral group I metabotropic glutamate receptors modulate nociception in mice. Nat Neurosci 2001; 4: 417-23

(6) Neugebauer V. 2002. Metabotropic glutamate receptors - important modulators of nociception and pain behaviour. Pain 2002; 98: 1-8

(7) Steckler T, Lavreysen H, Oliveira A M, Aerts N, Van Craenendonck H, Prickaerts J, et al. Effects of mGlu1 receptor blockade on anxiety-related behaviour in the rat lick suppression test. Psychopharmacology 2005; 179:198-206

(8) Pietraszek M, Sukhanov I, Maciejak P, Szyndler J, Gravius A, Wisłowska A, et al. Anxiolytic-like effects of mGlu1 and mGlu5 receptor antagonists in rats. Eur $J$ Pharmacol 2005; 514: 25-34

(9) Dravolina O A, Zakharova ES, Shekunova EV, Zvartau EE, Danysz W, Bespalov AY. mGlu1 receptor blockade attenuates cue- and nicotine-induced reinstatement of extinguished nicotine self-administration behavior in rats. Neuropharm 2007; 52: 263-9

(10) Belozertseva IV, Kos T, Popik P, Danysz W, Bespalov AY. Antidepressant-like effects of mGluR1 and mGluR5 antagonists in the rat forced swim and the mouse tail suspension tests. Eur Neuropsychoparm 2007; 17: 172-179 
(11)

Cargill M, Alktshuler D, Ireland J, Sklar P, Ardlie K, Patil N, et al. Characterization of single-nucleotide polymorphisms in coding regions of human genes. Nat Genet 1999; 22: $231-238$

Wang Z, Moult J. SNP's Protein structure and disease. Hum Mut 2001; 17: 263-270

(13) Green SA, Cole G, Jacinto M, Innis M, Liggett SB. A polymorphism of the human $\beta 2$ Adrenergic receptor within the fourth transmembrane domain alters ligand binding and functional properties of the receptor. J Biol Chem 1993; 266: 23116-23121.

(14) Mason DA, Moore D, Green SA, Liggett SB. A gain-of function polymorphism in a G-protein coupling domain of the human $\beta 1$ Adrenergic receptor. J Biol Chem 1999; 274: 12670-12674

(15) Small, KM, Forbes SL, Brown KM, Liggett SB. An Asn to Lys polymorphism in the third intracellular loop of the human A2A-Adrenergic receptor imparts enhanced agonist promoted $\mathrm{G}_{\mathrm{i}}$ coupling. J Biol Chem 2000; 275: 38518-38523.

(16) Downey PM, Lozza G, Petrò R, Diodato E, Foglia C, Bottazzoli F, et al. Ecdysonebased system for controlled inducible expression of metabotropic glutamate receptor subtypes 2, 5, and 8. J Biomol Screen. 2005; 10: 841-8

(17) Lavreysen H, Janssen C, Bischoff F, Langlois X, Leysen JE, Lesage AS. $[3 H] R 214127$ : a novel high-affinity radioligand for the mGlu1 receptor reveals a common binding site shared by multiple allosteric antagonists. Mol Pharmacol 2003; 63: 1082-93.

(18) Nickerson D A, Kolker N, Taylor S L. Sequence based detection of single nucleotide polymorphisms. Methods Mol Biol 2001;175: 29-35

(19) Cheng $\mathrm{Y}$, Prusoff $\mathrm{WH}$. Relationship between the inhibition constant $\left(\mathrm{K}_{\mathrm{i}}\right)$ and the concentration of inhibitor which causes 50 per cent inhibition $\left(I_{50}\right)$ of an enzymatic reaction. Biochem Pharmacol 1973; 22: 3099-108

(20) Kadushkin AV, Solovyeva NP, Granik VG. DMF diethyl acetal as a one-carbon component in the synthesis of isomeric pyridothienopyrimidines. Khim.-Farm Zh. 1993; 27: $5550-5553$ 
(21) Li L, Tomlinson R, Wang Y, Tsui H-C T, Chamberlain MJ, Johnson MP, et al. A novel series of potent and selective non competitive Antagonists of metabotropic glutamate receptor 1. Neuropharm 2002; 43: 273-318

(22) Lavreysen H, Wouters R, Bischoff F, Nòbrega Pereira S, Langlois X, et al. JNJ16259685, a highly potent, selective and systemically active mGlu1 receptor antagonist. Neuropharm 2004; 47: 961-972

(23) Evans WE, McLeod HL Pharmacogenomics - Drug disposition, drug targets, and side effects. New Eng J Med 2003; 348: 538-549

(24) Martinez FD, Graves PE, Baldini M, Solomon S, Erickson R. Association between genetic polymorphisms of the B2- Association between genetic polymorphisms of the B2adrenoceptor and response to albuterol in children with and without a history of wheezing. J Clin Invest 1997; 100: 3184-3188

(25) Van Essen GG, Rensma PL, de Zeeuw D, Sluiter WJ, Scheffer H, Apperloo AJ, de Jong PE. Association between angiotensin-converting-enzyme gene polymorphism and failure of renoprotective therapy. Lancet 1996; 347: 94-5

(26) Arranz M, Collier D, Sodhi M, Ball D, Roberts G, Price J, et al. Association between clozapine response and allelic variation in 5-HT2A receptor gene. Lancet 1995; 346: 281 282.

(27) Costantino G, Macchiarulo A, Belenikin M, Pellicciari R. Molecular dynamics simulation of the ligand binding domain of mGluR1 in response to agonist and antagonist binding. J Comput Aided Mol Des 2002; 16: 779-84.

(28) Francesconi A, Duvoisin RM. Role of the second and third intracellular loops of metabotropic glutamate receptors in mediating dual signal transduction activation. $J$ Biol Chem 1998; 273: 5615-5624.

(29) Havlickova M, Blahos J, Brabet I, Liu J, Hruskova B, Prézeau L, et al. The second intracellular loop of metabotropic glutamate receptors recognizes C termini of G-protein alpha-subunits. J Biol Chem 2003; 278: 63-70. 


\section{Figure Legends}

\section{Table 1}

Position and allele frequencies of non synonymous SNPs identified in the human mGluR1 receptor gene.

Table 2

Receptor densities and $\mathrm{K}_{d}$ values for the Wild type and S993 clones at varying ponasterone A concentrations, results were generated using the radiolabeled ligand $\left[{ }^{3} \mathrm{H}\right] \mathrm{SCH} 1041222$ and are expressed as means $( \pm$ SEM) from three independent experiments

Table 3

Functional activities of agonists and antagonists examined at the WT or S993 variant respectively, data are the mean $\mathrm{EC}_{50}$ values of agonists and $\mathrm{IC}_{50}$ values of antagonists determined from three independent experiments performed in quadruplicate, and are expressed as means \pm SEM.

Figure 1

Saturation binding experiments for $\left[{ }^{3} \mathrm{H}\right] \mathrm{SCH} 1041222$, in the absence or presence of ponasterone $A, \boldsymbol{a}$ and $\boldsymbol{b}$ are saturation binding curves from representative experiments from the WT and S993 cell lines respectively, $\mathbf{\square}$ un-induced, $\quad \boldsymbol{\Delta} 1 \mu \mathrm{M}, \boldsymbol{\nabla} 3 \mu \mathrm{M}$ and $\diamond 5 \mu \mathrm{M}$ of Ponasterone $\mathrm{A}$.

Figure 2

Competitive binding studies with selective mGluR1 antagonists, a JNJ 16259685 b LY456236, WT values are represented by an open square, and $S 993$ values by an open triangle, results are the means of three independent experiments. Data are normalized to the specific binding of the radiolabeled ligand $\left[{ }^{3} \mathrm{H}\right] \mathrm{SCH} 1041222$ observed in the absence of competitor $(\%$ Control).

Figure 3

Antagonism by $\bigcirc$ LY456236, $\square$ JNJ 16259685 and $\nabla$ SCH1041222 of Quisqualate stimulated calcium mobilisation in the WT and S993 expressing cell lines. Inhibition curves were constructed from the percentage responses pooled from three independent experiments performed in quadruplicate, values are means \pm SEM. Data are normalized to the response generated by the agonist in the absence of the antagonists.

Figure 4

Concentration response curves for the effect of $\square$ Quisqualate, $\triangle$ Glutamate and $\nabla$ DHPG on $\mathrm{Ca}^{2+}$ mobilisation in WT and $\mathrm{S} 993$ cell lines, values are means \pm SEM of quadruplicate determinations from a typical experiment. 
Table 1

\begin{tabular}{|c|c|c|c|c|c|c|c|c|}
\hline & & & & & $\begin{array}{l}\text { African } \\
\text { American }\end{array}$ & $\begin{array}{l}\text { African } \\
\text { American }\end{array}$ & Caucasian & Caucasian \\
\hline SNP & $\begin{array}{l}\text { Position } \\
\text { in cDNA }\end{array}$ & $\begin{array}{l}\text { Major } \\
\text { allele }\end{array}$ & $\begin{array}{l}\text { Minor } \\
\text { allele }\end{array}$ & $\begin{array}{l}\text { AA } \\
\text { Change }\end{array}$ & $\begin{array}{l}\text { Major } \\
(\%)\end{array}$ & $\begin{array}{l}\text { Minor } \\
(\%)\end{array}$ & $\begin{array}{l}\text { Major } \\
(\%)\end{array}$ & $\begin{array}{l}\text { Minor } \\
(\%)\end{array}$ \\
\hline g. $322791 A>C$ & 1345 & A & C & K449Q & 100 & 0 & 98.9 & 1.1 \\
\hline g.369607C>A & 2185 & C & A & P729T & 100 & 0 & 97.7 & 2.3 \\
\hline g.404379G $>A$ & 2785 & G & A & V929I & 98.9 & 1.1 & 96.7 & 3.3 \\
\hline g. $404571 \mathrm{~T}>\mathrm{C}$ & 2977 & C & $\mathrm{T}$ & P993S & 71.7 & 28.3 & 64.4 & 35.6 \\
\hline g.404637C>T & 3043 & C & $\mathrm{T}$ & P1015S & 98.9 & 1.1 & 100 & 0 \\
\hline g. $404701 \mathrm{G}>\mathrm{T}$ & 3107 & $\mathrm{G}$ & $\mathrm{T}$ & G1036V & 98.9 & 1.1 & 100 & 0 \\
\hline g. $404755 \mathrm{G}>A$ & 3161 & G & A & G1054D & 98.9 & 1.1 & 100 & 0 \\
\hline g. $404808 C>G$ & 3214 & C & G & P1072A & 96.7 & 3.3 & 100 & 0 \\
\hline
\end{tabular}


Table 2

\begin{tabular}{lllll}
\hline & $\begin{array}{l}\mathrm{B}_{\text {Max }}(\mathrm{fmol} / \mathrm{mg} \\
\text { protein) }\end{array}$ & $\mathrm{Kd}(\mathrm{nM})$ & $\begin{array}{l}\mathrm{B}_{\text {Max }}(\mathrm{fmol} / \mathrm{mg} \\
\text { protein) }\end{array}$ & $\mathrm{Kd}(\mathrm{nM})$ \\
\hline $\begin{array}{l}\text { Ponasterone } \mathrm{A} \\
(\mu \mathrm{M})\end{array}$ & & & & \\
0 & $136.7( \pm 67)$ & $3.4( \pm 0.76)$ & $145.8( \pm 50)$ & $3.5( \pm 0.47)$ \\
1 & $799.4( \pm 147)$ & $3.8( \pm 0.44)$ & $217.2( \pm 87)$ & $4.5( \pm 0.61)$ \\
3 & $1603( \pm 223)$ & $4.0( \pm 0.51)$ & $707.7( \pm 157)$ & $4.8( \pm 0.67)$ \\
5 & $1951( \pm 354)$ & $4.9( \pm 0.49)$ & $1551( \pm 270)$ & $3.8( \pm 0.51)$ \\
\hline
\end{tabular}


Table 3

\begin{tabular}{llll}
\hline & WT & \multicolumn{3}{l}{ S993 } \\
\hline Agonist Potencies $(\mu \mathrm{M})$ & & & \\
Quisqualate & $0.0215( \pm 0.012)$ & $0.0241( \pm 0.009)$ \\
Glutamate & $0.460 \quad( \pm 0.18)$ & $0.340 \quad( \pm 0.14)$ \\
DHPG & 1.79 & $( \pm 0.73)$ & $1.64 \quad( \pm 0.12)$ \\
& & & \\
\hline Antagonist Potencies $(\mu \mathrm{M})$ & & & \\
& & & \\
JNJ1625968 & $0.0023( \pm 0.0008)$ & $0.0031( \pm 0.0012)$ \\
SCH1041222 & $0.0047( \pm 0.0012)$ & $0.0052( \pm 0.0014)$ \\
LY456236 & 0.267 & $( \pm 0.120)$ & $0.445( \pm 0.145)$ \\
\hline
\end{tabular}


Figure 1
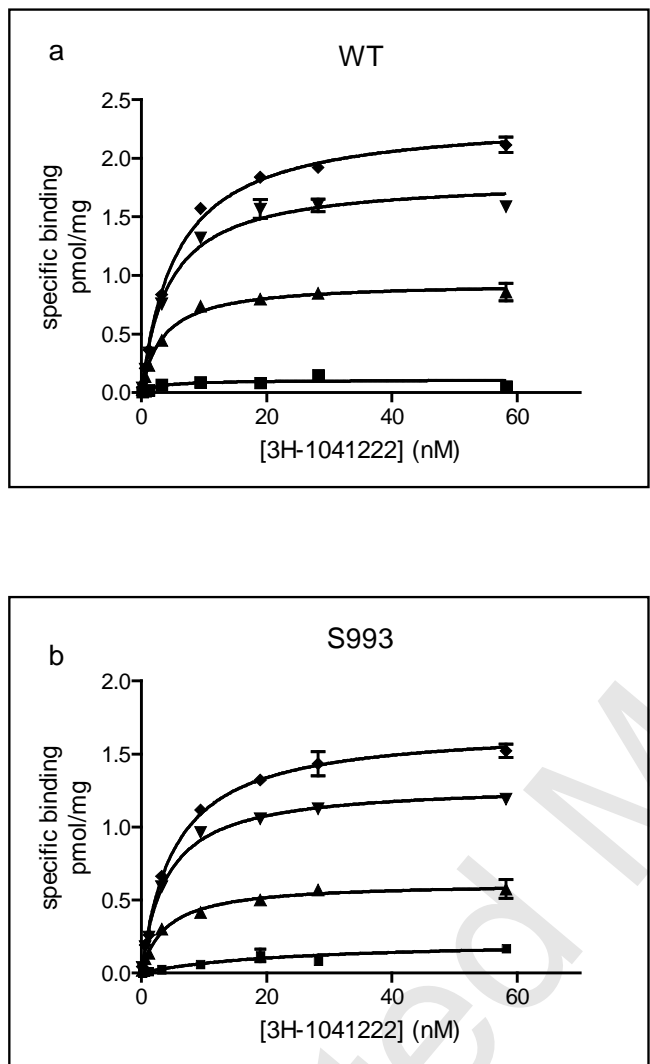
Figure 2

a

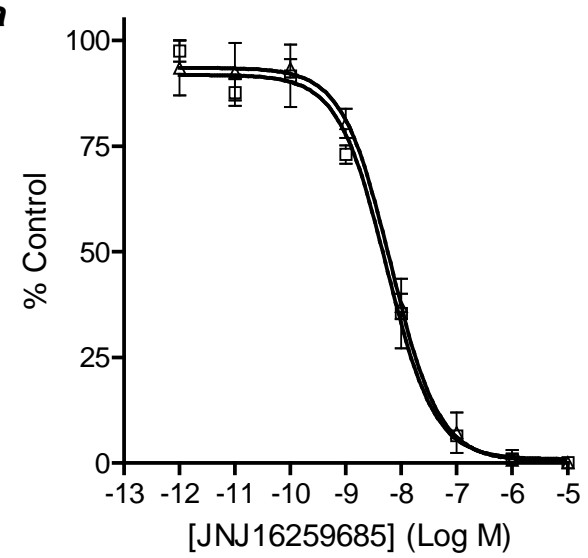

b

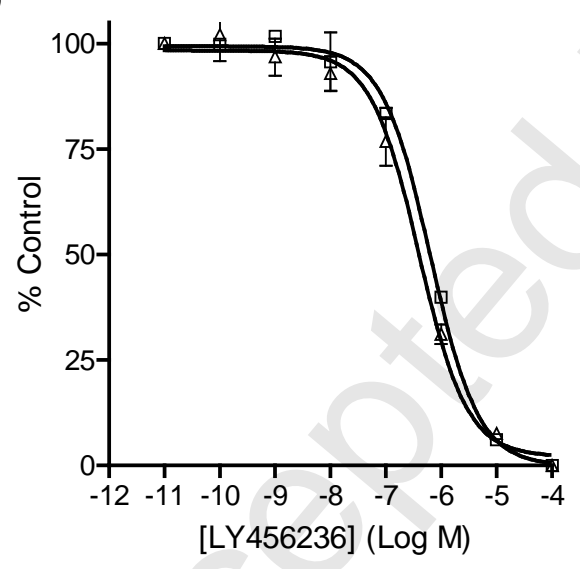

Page 21 of 24 
Figure 3
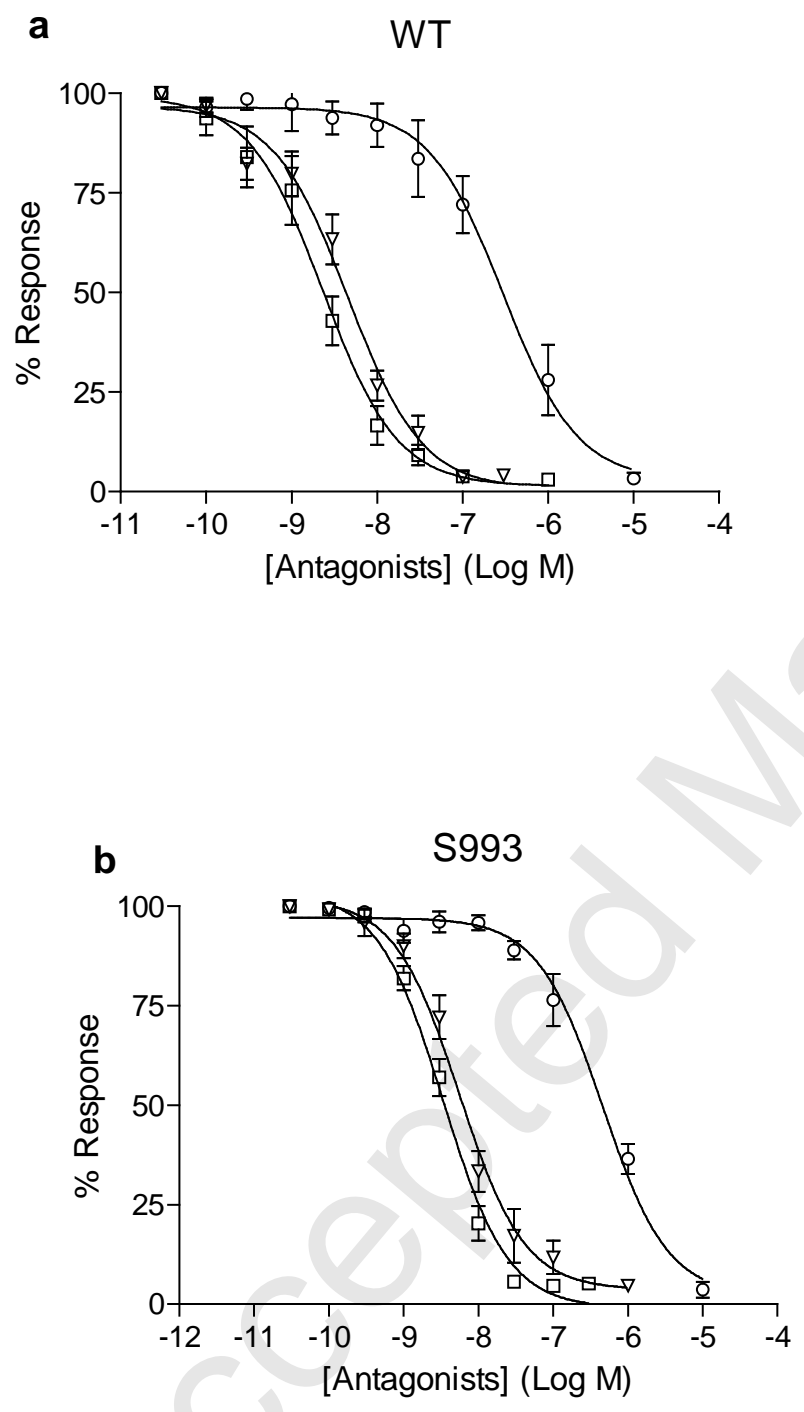
Figure 4
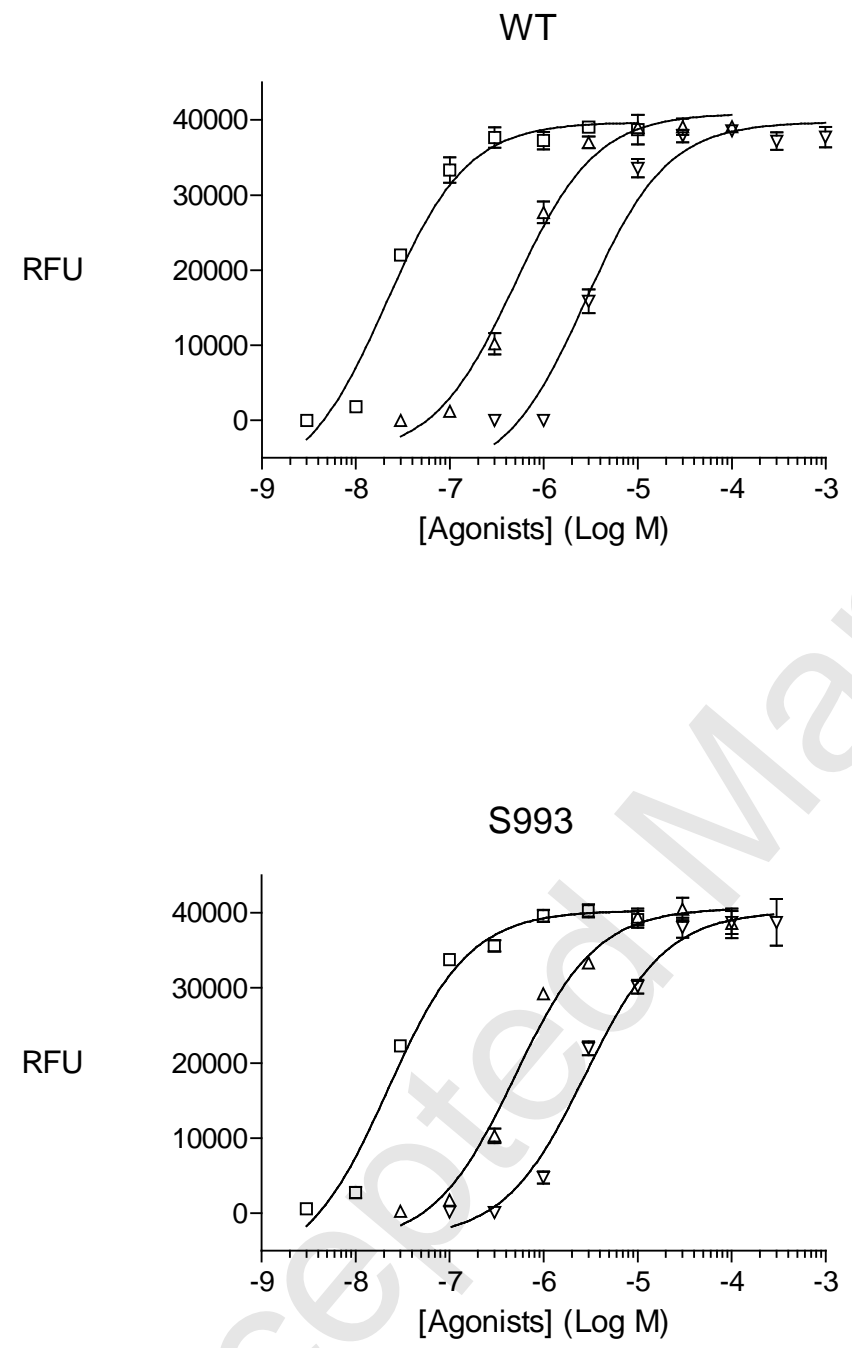
Synonymous SNPs are numerous but infrequent in the human MGLUR1 gene, they are unlikely to affect the efficacy of antagonists if and when these reach the clinic

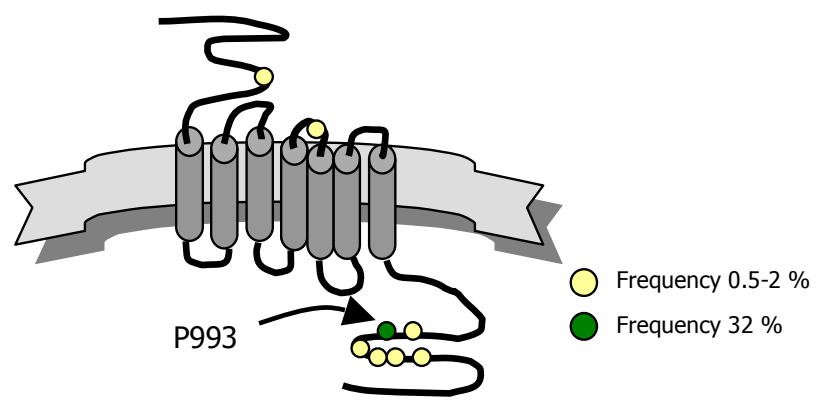

